\title{
Do Active and Passive Antipredator Defences in the Toad Epidalea calamita Differ between Males and Females from Natural Habitats and Agrosystems?
}

\author{
Francisco Javier Zamora-Camacho ${ }^{1,2}$ (D) \\ 1 Departamento de Sistemas Físicos, Químicos y Naturales, Universidad Pablo de Olavide, Carretera de Utrera km 1, \\ 41080 Seville, Spain; zamcam@ugr.es \\ 2 Departamento de Biodiversidad, Ecología y Evolución, Facultad de Ciencias Biológicas, \\ Universidad Complutense de Madrid, C/José Antonio Novais 12, 28040 Madrid, Spain
}

Citation: Zamora-Camacho, F.J. Do Active and Passive Antipredator Defences in the Toad Epidalea calamita Differ between Males and Females from Natural Habitats and

Agrosystems? Diversity 2021, 13, 614. https://doi.org/10.3390/d13120614

Academic Editor: Michael Wink

Received: 6 November 2021

Accepted: 23 November 2021

Published: 25 November 2021

Publisher's Note: MDPI stays neutral with regard to jurisdictional claims in published maps and institutional affiliations.

Copyright: (C) 2021 by the author. Licensee MDPI, Basel, Switzerland. This article is an open access article distributed under the terms and conditions of the Creative Commons Attribution (CC BY) license (https:/ / creativecommons.org/licenses/by/ $4.0 /)$.

\begin{abstract}
Due to their assumed costs, simultaneous antipredator strategies are expected to face trade-offs, which, however, could be milder in individuals subjected to a more intense predator pressure. In this work, I studied the relationship between locomotion and parotoid glands in the natterjack toad, Epidalea calamita. Specifically, I predicted that individuals with reduced sprint speed would rely more on their chemical defences, having larger and more aposematically coloured parotoid glands. In addition, I expected this trade-off to be more evident in females and toads from pine grove habitats, because, according to previous work, males and toads from agrosystems are under greater predator pressure. However, sprint speed showed no relationship with coloration, but toads with proportionally greater parotoid glands were also proportionally faster. Thus, the costs of these antipredator traits might not be high enough to make them interfere, or the benefits of simultaneous optimisation of sprint speed and parotoid gland size might outweigh the costs of it in some individuals. In any case, habitat and sex did not affect these relationships, so the trends detected are valid across sexes and the habitats studied.
\end{abstract}

Keywords: aposematism; Epidalea calamita; locomotor performance; parotoid glands; sprint speed

\section{Introduction}

Predators are major agents of selection on their prey [1,2]. First and foremost, the future fitness of an individual that is preyed on is reduced to zero [3,4]. Moreover, failed predator attacks may damage fitness in diverse ways $[5,6]$ : they might result in wounds and injuries of varying degrees of seriousness, which may lead to reduced mobility and thus greater susceptibility to future predator attacks [7], or to infections that may compromise health and survival [8]. Last but not least, predator threats can promote the expression of inducible antipredator defences that, be they behavioural [9], physical [10], or chemical [11], usually come with costs, primarily in terms of time [12] or energy consumption [13]

Other antipredator defences are also not devoid of costs. Perhaps along with concealment, the most widespread antipredator strategy in the animal kingdom is flight: when faced with an imminent enemy, most animals actively flee towards the safety of a refuge [14,15]. Accordingly, the available evidence supports a positive relationship between locomotor performance and fitness in multiple animal taxa, in which not only predator avoidance, but also prey capture, dispersal, or intraspecific interactions might be involved [16-18]. However, the muscular exertion linked to locomotion also implies some costs. Energy consumption is probably the most obvious of these [19,20]. Besides, the production of reactive oxygen species as a consequence of the physiological processes involved may unbalance the oxidative metabolism, resulting in oxidative stress [21,22], which may ultimately have noxious effects on physiological homeostasis and animal health [23]. Moreover, particularly in cryptic species, individuals that are in motion have greater chances to 
be detected by predators, and thus attacked, than those that remain immobile, so they tend not to flee until detected $[24,25]$.

Other kinds of antipredator defences are no exception to this interplay between benefits and costs. Such is the case of chemical defences, which are poisonous or unpalatable substances that act as deterrents against predators [26-28]. Their benefits notwithstanding, these substances are costly to synthetize, as the metabolic routes involved require both energy and metabolites that may be limiting $[29,30]$. These chemical defences are oftentimes accompanied by aposematic colorations, which resort to salient colours and patterns that warn potential predators $[11,31,32]$ and discourage them from attacking and/or remind them of past unpleasant experiences, thus avoiding the damage associated with such an attack $[33,34]$. However, the synthesis of the pigments needed for salient colorations, especially carotenoids and melanin, also incurs well-documented metabolic costs $[35,36]$.

Although simultaneously bearing several antipredator defences could a priori appear as mostly beneficial, their additive costs could be difficult to satisfy. Therefore, animals with various antipredator defences could trade them off. Nonetheless, these trade-offs could be milder when the benefits of these defences outweigh their costs, which could happen under intense predation pressure.

In this work, I tested these predictions on the natterjack toad, Epidalea calamita (Laurenti, 1768). This is a cursorial toad that escapes predators by means of quick runs [37]. Moreover, it has prominent parotoid glands. These are a pair of swollen dorsal structures that lay behind the heads of numerous amphibian species, and whose size is directly proportional to the amounts of chemical defences they release [38,39]. The production of chemical defences in the parotoid glands is energetically costly, and trades off with several traits, such as growth rate and dispersal, in other closely related species [40]. In the case of E. calamita, these glands are aposematic: the chances of predator attacks decrease with the increasing degree of divergence between parotoid gland and dorsum colour in plasticine models [41]. Moreover, plasticine models exposed in agrosystems receive more predator attacks than those placed in pine grove, supporting the idea that agrosystem toads are under greater predation pressure [41]. Therefore, I predict that both parotoid gland size and colour saliency will be negatively correlated with sprint speed due to energy trade-offs among these. In other words, I expect slower individuals to be more reliant on their chemical defences, thus having greater and/or more salient parotoid glands. However, because predation pressure is greater in agrosystems, I expect these trade-offs to be stronger or only apparent in pine grove toads in comparison, as the former could benefit from greater investment in antipredator defences. Additionally, males in this species have larger parotoid glands than females [41], and are faster [37], which could be responses to greater predation pressure. Indeed, males appear under greater predation pressure in the closely related toad Bufo bufo [42]. Therefore, greater exposure to predators may reduce this trade-off in males as compared to females.

\section{Materials and Methods}

\subsection{Study Species}

The natterjack toad (E. calamita) is a medium-size bufonid (48-82 $\mathrm{mm}$ snout-vent length, hereafter, SVL, in the sample studied here) that occurs in vast regions of central and western Europe [43]. Within its distribution area, this species occupies a wide variety of habitats, including natural as well as human-altered landscapes [43]. Given the notable divergence in the climatic conditions among these regions, phenology is subjected to spatial variation: toads hibernate in cold zones but aestivate instead in dry areas [43]. Activity takes place in rainy or very humid, not too cold nights, and the reproductive period may span from winter in warm regions to spring in colder environments [43]. Other than that, toads remain inactive under logs or rocks, or in burrows they dig if the ground is loose enough, where they are sheltered against predators [43]. Natterjack toads are common prey to visual and olfactory predators: snakes such as Natrix maura and N. astreptophora, birds such as Larus ridibundus or Pica pica and mammals such as Meles meles, among others, are 
known to feed on these toads [43]. Commonly, when confronting a predator, toads quickly flee by means of intermittent runs [37]. In other cases, especially if cornered, they bend their bodies and expose their conspicuous parotoid glands, capable of releasing toxins in remarkable amounts [44].

\subsection{Toad Capture and Management}

Fieldwork took place in Pinares de Cartaya pine grove (SW Spain: $37^{\circ} 20^{\prime} \mathrm{N}, 7^{\circ} 09^{\prime} \mathrm{W}$ ) and surrounding agrosystems. The former consists of an 11,000 ha Pinus pinea grove whose understory is dominated by Pistacea lentiscus, Cistus ladanifer and Rosmarinus officinalis. Although the native or introduced origin of this vegetal formation is debatable, it has been predominant in this area for at least the last 4000 years, being thus considered a natural habitat [45]. This pine grove is surrounded by a 2800 ha crop area, some $5 \mathrm{~km}$ away, which, during the past decades, has transitioned from extensive vegetable farms to intensive strawberry, blueberry and orange tree (among others) agrosystems. In these agrosystems, landowners add agrochemicals such as fungicides, herbicides, pesticides or fertilizers at their discretion, and summer drought, which spans approximately from May/June to September/October, is tempered by artificial irrigation.

In this area, E. calamita reproduces during the winter. Therefore, toad capture took place from December 2018 to March 2019. In total, I captured 25 males and 21 females in the pine grove, plus 20 males and 22 females in the agrosystem. I caught these toads by hand while they were active on rainy nights, after which I transported them to the laboratory in plastic buckets with a lid with holes and damp earth as a substrate. Once in the laboratory, I sexed these toads based on colour sexual dimorphism (males are greener and have pinkish or purplish vocal sacs, whereas females are browner and have greyish throats [46]) and on the presence of dark and rough nuptial pads only in males [43]. Then, I housed the toads in individual plastic containers $(20 \times 13 \times 9 \mathrm{~cm})$ with humid peat substrate and a piece of opaque plastic as a refuge.

\subsection{Coloration and Morphological Measurements}

Within $24 \mathrm{~h}$ from capture, I measured their SVL with a ruler, to the nearest $\mathrm{mm}$, and I took an orthogonal photograph of each toad's dorsum with a photo camera Canon EOS $550 \mathrm{D}$ at a maximum resolution of 18 megapixels, with a shutter-aperture of F10 and a fixed focal length of $53 \mathrm{~mm}$. Exposure time, by contrast, was automatically adjusted by the device to optimise colour capture in each case. Perpendicularity and stability were assured with a tripod which allowed a steady distance of $40 \mathrm{~cm}$ between the lens and the photographed surface. This surface consisted of a horizontal square $(30 \mathrm{~cm}$ side) of white paper. Three vertical white polyester squares $(30 \mathrm{~cm}$ side) sat respectively on both sides and the rear of this surface, turning it into an incomplete cube where the front and the upper sides were missing: the open front side allowed toad handling, and the open upper side allowed photographs from above. Externally from each lateral polyester square, an $80 \mathrm{~W}$ white-light bulb at a height of $20 \mathrm{~cm}$ provided the scene with bidirectional illumination that prevented shades. Plus, the fact that those white-light bulbs filtered by white polyester were the only light sources in the room (photos were taken at night, in a completely closed room) eliminated any parasitic light that could have altered colour recording. After fixing the camera to the aforementioned parameters, but before photos were taken, white balance was calibrated to a clean piece of paper. Then, a piece of graph paper for biometric measures and a standardised colour chart (IMAGE Photographic) for colour calibration were placed on the photographed surface, close to the toad itself. Dust and humidity were removed from toads' skins with a disposable napkin prior to each photo.

These photos were then analysed with the software Adobe Photoshop CS5, after calibrating white balance again in each photo by applying the grey eyedropper in the white balance calibration function on the colour chart. Moreover, I set the colour mode to the $L^{*} a^{*} b^{*}$ three-dimensional colour space described by the Commision Internationale $\mathrm{d}^{\prime}$ Eclairage (CIE) [47]. In this colour space, $\mathrm{L}^{*}$ is a measure of lightness, and spans from 
0 (pure black) to 100 (pure white), $\mathrm{a}^{*}$ represents the green-red axis (negative values are green and positive values are red) and $b^{*}$ represents the blue-yellow axis (negative values are blue and positive values are yellow). Afterwards, I used the piece of graph paper to calibrate length, and manually delimited both parotoid glands with the lasso tool so as to calculate the sum of both parotoid glands' area. Next, I averaged the colours of each parotoid gland as previously selected and used the histogram tool to gather the average $L^{*}, a^{*}$ and $b^{*}$ values of both. Finally, following the same methods, I demarcated the dorsum, leaving the parotoid glands out, averaged its colour and gathered its $\mathrm{L}^{*}, \mathrm{a}^{*}$ and $\mathrm{b}^{*}$ values. With these values, I calculated parotoid gland colour saliency $\left(\Delta \mathrm{E}^{*}\right)$ by applying the formula $\Delta \mathrm{E}^{*}=\left(\Delta \mathrm{L}^{*} 2+\Delta \mathrm{a}^{*} 2+\Delta \mathrm{b}^{*} 2\right) 1 / 2$ to $\mathrm{L}^{*}$, $\mathrm{a}^{*}$ and $\mathrm{b}^{*}$ parameters of parotoid glands and dorsum, as the CIE proposes [48,49].

\subsection{Sprint Speed Measurement}

Sprint speed trials were conducted $48 \mathrm{~h}$ after these photos were taken. Toads spent this time in the individual plastic containers previously described. One hour before the trials, I gently but firmly pressed each toad's lower abdomen to empty their bladders [50,51]. In this way, I reduced to zero, and thus standardised, bladder water burden, which could affect locomotion [50-52]. Then, toads were allowed to rest in their containers for one hour, after which I recorded them (with a video camera Canon EOS 550D, set at 25 frames per second) while individually running in a brown cardboard linear runway $(200 \times 15 \times 15 \mathrm{~cm})$. The bottom of this runway was divided into $10 \mathrm{~cm}$ stretches with perpendicular white stripes whose colour contrasted with the brown cardboard, so that both limits of each stretch could be accurately discerned in the video. The cardboard surface was rough enough to favour traction, which is relevant because the substrate may affect locomotion [53]. Moreover, a black background at one end of the runway was intended to be mistaken for a shelter and encourage toads to move forward. Toads were released at the other end of the runway, and manually chased constantly but gently, in order to stimulate their moving forward, until they reached the end of the runway. Since temperature may affect amphibian motility [54], room temperature was roughly constant $\left(19^{\circ} \mathrm{C}\right)$ throughout the process. Trials were always conducted at night, when toads are naturally active. Illumination was also standardised with a $60 \mathrm{~W}$ bulb located $2.5 \mathrm{~m}$ above the centre of the runway. After the trials, I released the toads at their capture sites as soon as possible. Toads suffered no visible damage as a consequence of this study.

Then, I used the software Tracker v. 4.92 for frame-by-frame video analysis. Specifically, I recorded the time (precision: $0.01 \mathrm{~s}$ ) toads used to cover every stretch, i.e., the time toads spent between the perpendicular strips delimiting both ends of each stretch $[37,55,56]$. Since stretch length was known $(10 \mathrm{~cm})$, I could calculate the speed (in $\mathrm{cm} / \mathrm{s}$ ) of each toad in each stretch by dividing $10 \mathrm{~cm}$ by the time (s) needed to cover it. Finally, I considered the fastest value of each toad as its sprint speed.

\subsection{Statistics}

In order to control for the effect of body size on parotoid gland area and on sprint speed, I calculated the residuals of the simple regressions of parotoid gland area and of sprint speed on SVL, whereas parotoid colour saliency was analysed untransformed. After checking the assumptions of homoscedasticity and residual normality, I applied parametric statistics [57]. The residuals of sprint speed on SVL needed to be square-root-transformed so as to be homoscedastic. Data were analysed with the software Statistica v8.0.

Firstly, I conducted an ANCOVA, where the residuals of sprint speed on SVL (squareroot-transformed) were the response variable, the residuals of parotoid gland area on SVL were the covariates and habitat and sex were included as factors. The interactions among all covariates and factors were included in the full model (presented as Supplementary Material), to which stepwise backward selection was applied.

Then, I performed a similar ANCOVA where the residuals of sprint speed on SVL (square-root-transformed) were the response variable, parotoid colour saliency was the 
covariate and habitat and sex were included as factors. The interactions among all covariates and factors were included in the full model (presented as Supplementary Material), to which stepwise backward selection was applied.

\section{Results}

\subsection{Parotoid Gland Area}

The full model detected that the residuals of sprint speed on SVL were greater in males than in females, and positively related to the residuals of parotoid gland area on SVL, whereas the effects of habitat and all the interactions were non-significant (Tables S1 and S2, Supplementary Material). The final model after stepwise backward selection maintained the effects of $\operatorname{sex}\left(F_{1,85}=9.508 ; p=0.003\right)$ and the residuals of parotoid gland area on SVL $\left(F_{1,85}=10.090 ; \beta=0.310 ; p=0.002 ;\right.$ Figure 1$)$.

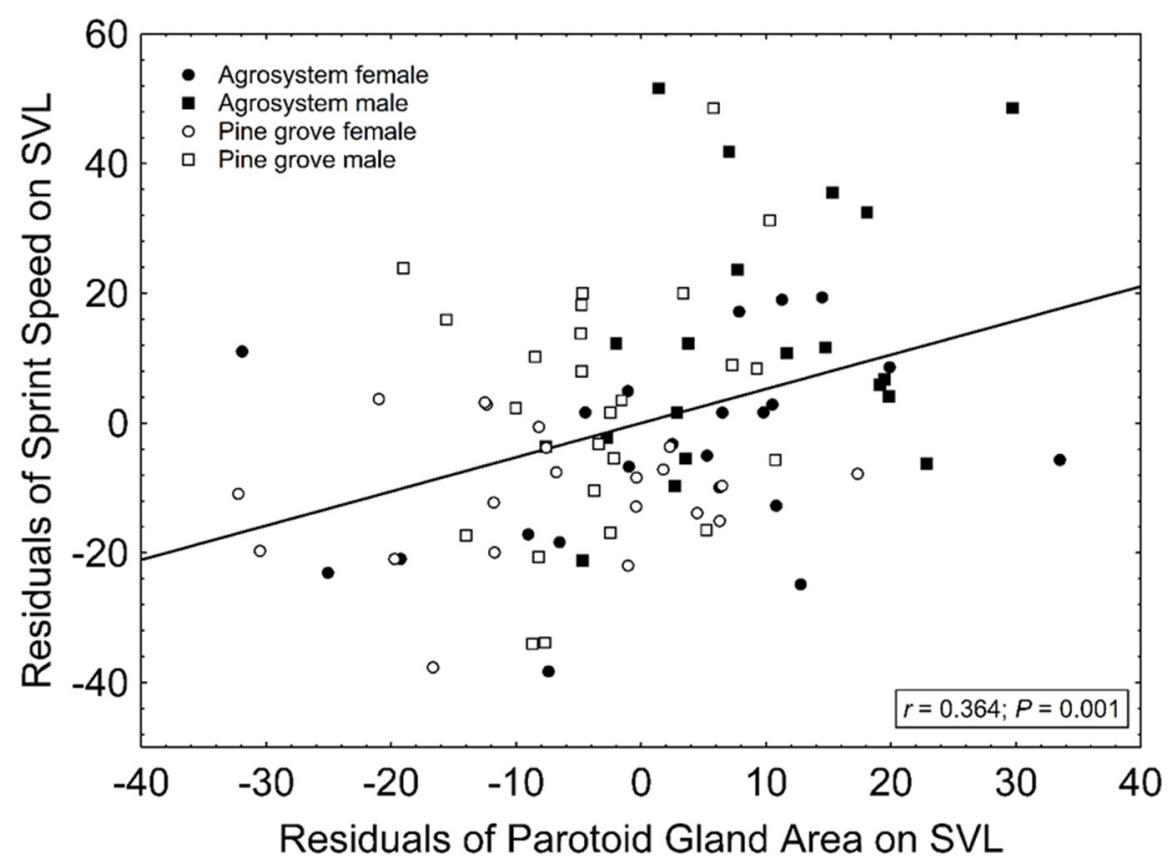

Figure 1. Correlation between the residuals of sprint speed on SVL and the residuals of parotoid gland area on SVL. $\mathrm{r}$ and $p$ values are indicated.

\subsection{Parotoid Gland Colour Saliency}

The full model detected no effect of either of the factors, the covariate, or their interactions on the residuals of sprint speed on SVL (Tables S3 and S4, Supplementary Material). In the final model after stepwise backward selection, only the effects of $\operatorname{sex}\left(F_{1,85}=14.214\right.$; $p<0.001)$ and habitat $\left(F_{1,85}=4.049 ; p=0.047\right)$ were significant.

\section{Discussion}

These results challenge both the fundamental predictions on which this work was based. To begin with, they provide no evidence of a trade-off between sprint speed and parotoid gland colour saliency or size. Contrary to what was expected, slower toads do not invest more in colour signalling of their parotoid glands. What is more, whereas sprint speed appears unrelated to parotoid gland colour saliency, it is directly proportional to parotoid gland size. Not only does such a result not match the expectations, but it reverses them: individuals that are faster also have larger parotoid glands. Therefore, some toads are allegedly better suited against their predators and simultaneously optimise both these characteristics.

The absence of a trade-off between these antipredator strategies could imply that their costs are not high enough to interfere with each other's development. Remarkably, locomotion also remains unaltered despite immune system activation in other amphibians, which 
might highlight its antipredator worthiness [58]. Indeed, evidence has been detected that prey locomotion mode affects other antipredator strategies, such as the escape tactic [59]. An alternative, but non-mutually exclusive explanation, could be that individuals under greater predation risk offset or even overcompensate the potential trade-offs among these traits by increasing food consumption, as has been observed in birds [60]. Indeed, food restriction exacerbates energy-based trade-offs in nematodes [61].

Additionally, the fitness benefits of maximizing sprint speed (assuming that its antipredator role does not conflict with its other roles, for example, in food acquisition, dispersal, or intraspecific relationships) and parotoid gland size at the same time could outweigh the energy costs of it in individuals under greater predation risk. Previous pieces of research have independently established that, in this system, E. calamita males are faster [37] and possess larger parotoid glands [41] than females. Moreover, these glands are larger in agrosystem than in pine grove individuals [41]. Extensive scientific literature on this $[37,41,62,63]$ and other species $[64,65]$ suggests that male toads are more conspicuous than females, probably as a consequence of male competition for females, and thus might undergo greater predation pressure [42]. Moreover, plasticine models of toads receive more predator attacks in agrosystems than in pine grove in this system [41]. Therefore, it could be assumed that the positive correlation between sprint speed and parotoid gland size could be a consequence of males being faster and possessing larger parotoid glands than females. However, this effect was already present in the full ANOVA prior to stepwise backward selection, where sex, habitat and their interactions with the residuals of parotoid gland size were controlled for and proved non-significant. Therefore, the positive relationship between sprint speed and parotoid gland size is valid across sexes and habitats rather than a mere by-product of sexual dimorphism in speed and parotoid gland size and/or habitat divergence in the latter. This result contrasts with findings on other taxa, such as Centruroides vittatus scorpions, where slower individuals make more frequent use of their venomous stings, which leads to sexual dimorphism in antipredator responses: females, which are slower, tend to attack with their stings at greater rates than males, which are faster and tend to flee more often than females [66].

Moreover, unlike the case herein, antipredator strategies and the relationships among them are known to be subjected to spatial variation in numerous species, according to predator pressure (reviewed in [67]). Specific antipredator strategies [68] and the relationships among them can vary according to the actual predation risk [69]. However, constraints to such spatial adjustments may exist, either genetic- or trade-off-based [67]. Although the reasons remain obscure, in the case studied here, however, there is no evidence of spatial variation in the relationships (or the lack thereof) of sprint speed with parotoid gland size and coloration.

To conclude, no trade-off could be detected between sprint speed and parotoid gland size or coloration. Instead, sprint speed showed no relationship with coloration, but a positive one with the size of these glands, which reverses the expected trend. This finding could imply that the costs of these antipredator strategies are not high enough to make them interfere, or even that the benefits of the simultaneous optimisation of sprint speed and parotoid gland size outweigh the costs of it in some individuals. In any case, habitat and sex do not affect these relationships, which suggests that the trends detected are valid across sexes and the habitats studied, with no evidence of separate evolution.

Supplementary Materials: The following are available online at https:/ / www.mdpi.com/article/ 10.3390/d13120614/s1: Tables S1-S4: Dataset.

Funding: This research received no external funding.

Institutional Review Board Statement: The study was conducted according to the guidelines of the Declaration of Helsinki and approved by the Institutional Review Board of Junta de Andalucía (protocol code AWG/mgd GB-369-20, 23 November 2018).

Informed Consent Statement: Not applicable. 
Data Availability Statement: Data are contained as Supplementary Material.

Acknowledgments: Gregorio Moreno-Rueda and Mar Comas kindly provided logistic support. Comments by three anonymous reviewers improved the text.

Conflicts of Interest: The author declares no conflict of interest.

\section{References}

1. Abrams, P.A. The evolution of predator-prey interactions: Theory and evidence. Ann. Rev. Ecol. Syst. 2000, 31, 79-105. [CrossRef]

2. Creel, S.; Christianson, D. Relationships between direct predation and risk effects. Trends Ecol. Evol. 2008, 23, 194-201. [CrossRef]

3. Lima, S.L. Putting predators back into behavioral predator-prey interactions. Trends Ecol. Evol. 2002, 17, 70-75. [CrossRef]

4. Beauchamp, D.A.; Wahl, D.; Johnson, B.M. Predator-prey interactions. In Analysis and Interpretation of Inland Fisheries Data; Guy, C.S., Brown, M.J., Eds.; American Fisheries Society: Bethesda, MD, USA, 2007.

5. Zamora-Camacho, F.J.; Aragón, P. Failed predator attacks have detrimental effects on antipredatory capabilities through developmental plasticity in Pelobates cultripes toads. Funct. Ecol. 2019, 33, 846-854. [CrossRef]

6. Wirsing, A.J.; Heithaus, M.R.; Brown, J.S.; Kotler, B.P.; Schmitz, O.J. The context dependence of non-consumptive predator effects. Ecol. Lett. 2021, 24, 113-129. [CrossRef]

7. Ding, G.H.; Lin, Z.H.; Zhao, L.H. Locomotion and survival of two sympatric larval anurans, Bufo gargarizans (Anura: Bufonidae) and Rana zhenhaiensis (Anura: Ranidae), after partial tail loss. Zoologia 2014, 31, 316-322. [CrossRef]

8. Archie, E.A. Wound healing in the wild: Stress, sociality and energetic costs affect wound healing in natural populations. Paras. Immunol. 2013, 35, 374-385. [CrossRef] [PubMed]

9. Bliss, M.M.; Cecala, K.K. Terrestrial salamanders alter antipredator behavior thresholds following tail autotomy. Herpetologica 2017, 73, 94-99. [CrossRef]

10. Kishida, O.; Nishimura, K. Multiple inducible defences against multiple predators in the anuran tadpole, Rana pirica. Evol. Ecol. Res. 2005, 7, 619-631.

11. Zvereva, E.L.; Kozlov, M.V. The costs and effectiveness of chemical defenses in herbivorous insects: A meta-analysis. Ecol. Monogr. 2016, 86, 107-124. [CrossRef]

12. Creel, S.; Winnie, J.A.; Christianson, D.; Liley, S. Time and space in general models of antipredator response: Tests with wolves and elk. Anim. Behav. 2008, 76, 1139-1146. [CrossRef]

13. Van Buskirk, J. The costs of an inducible defense in anuran larvae. Ecology 2000, 81, 2813-2821. [CrossRef]

14. Watkins, T.B. Predator-mediated selection on burst swimming performance in tadpoles of the Pacific tree frog, Pseudacris regilla. Physiol. Zool. 1996, 69, 154-167. [CrossRef]

15. McGee, M.R.; Julius, M.L.; Vajda, A.M.; Norris, D.O.; Barber, L.B.; Schoenfuss, H.L. Predator avoidance performance of larval fathead minnows (Pimephales promelas) following short-term exposure to estrogen mixtures. Aquat. Toxicol. 2009, 91, 355-361. [CrossRef] [PubMed]

16. Meyer-Vernet, N.; Rospars, J.P. Maximum relative speeds of living organisms: Why do bacteria perform as fast as ostriches? Phys. Biol. 2016, 13, 066006. [CrossRef] [PubMed]

17. Lailvaux, S.P.; Husak, J.F. Predicting life-history trade-offs with whole-organism performance. Integr. Comp. Biol. 2017, 57, 325-332. [CrossRef]

18. Kraskura, K.; Nelson, J.A. Hypoxia and sprint swimming performance of juvenile striped bass, Morone saxatilis. Physiol. Biochem. Zool. 2018, 91, 682-690. [CrossRef]

19. Taylor, C.R.; Heglund, N.C.; McMahon, T.A.; Looney, T.R. Energetic cost of generating muscular force during running. A comparison of large and small animals. J. Exp. Biol. 1980, 86, 9-18. [CrossRef]

20. Brijs, J.; Sandblom, E.; Sundh, H.; Gräns, A.; Hinchcliffe, J.; Ekström, A.; Sundell, K.; Olsson, C.; Axelsson, M.; Pichaud, N. Increased mitochondrial coupling and anaerobic capacity minimizes aerobic costs of trout in the sea. Sci. Rep. 2017, 7, 45778. [CrossRef]

21. Fisher-Wellman, K.; Bloomer, R.J. Acute exercise and oxidative stress: A 30 year history. Dyn. Med. 2009, 8, 1. [CrossRef]

22. Sorci, G.; Faivre, B. Inflammation and oxidative stress in vertebrate host-parasite systems. Philos. Trans. R. Soc. B 2009, 364, 71-83. [CrossRef]

23. Halliwell, B.; Gutteridge, J.M.C. Free Radicals in Biology and Medicine; Oxford University Press: Oxford, UK, 2007.

24. Krause, J.; Godin, J.G.J. Predator preferences for attacking particular prey group sizes: Consequences for predator hunting success and prey predation risk. Anim. Behav. 1995, 50, 465-473. [CrossRef]

25. Geipel, I.; Kernan, C.E.; Litterer, A.S.; Carter, G.G.; Page, R.A.; ter Hofstede, H.M. Predation risks of signalling and searching: Bats prefer moving katydids. Biol. Lett. 2020, 16, 20190837. [CrossRef] [PubMed]

26. Mebs, D. Toxicity in animals. Trends in evolution? Toxicon 2001, 39, 87-96. [CrossRef]

27. Brodie, E.D., III. Toxins and venoms. Curr. Biol. 2009, 19, R931-R935. [CrossRef] [PubMed]

28. Savitzky, A.H.; Mori, A.; Hutchinson, D.A.; Saporito, R.A.; Burghardt, G.M.; Lillywhite, H.B.; Meinwald, J. Sequestered defensive toxins in tetrapod vertebrates: Principles, patterns, and prospects for future studies. Chemoecology 2012, 22, 141-158. [CrossRef]

29. Bowers, M.D. The evolution of unpalatability and the cost of chemical defense in insects. In Insect Chemical Ecology: An Evolutionary Approach; Roitberg, B.D., Isman, M.B., Eds.; Chapman \& Hall: New York, NY, USA, 1992. 
30. Zvereva, E.L.; Zverev, V.; Kruglova, O.Y.; Kozlov, M.V. Strategies of chemical anti-predator defences in leaf beetles: Is sequestration of plant toxins less costly than de novo synthesis? Oecologia 2017, 183, 93-106. [CrossRef]

31. Saporito, R.A.; Zuercher, R.; Roberts, M.; Gerow, K.G.; Donnelly, M.A. Experimental evidence for aposematism in the Dendrobatid poison frog Oophaga pumilio. Copeia 2007, 2007, 1006-1011. [CrossRef]

32. Ruxton, G.D.; Allen, W.L.; Sherratt, T.N.; Speed, M.P. Avoiding Attack: The Evolutionary Ecology of Crypsis, Aposematism, and Mimicry; Oxford University Press: New York, NY, USA, 2018.

33. Skelhorn, J.; Rowe, C. Avian predators taste-reject aposematic prey on the basis of their chemical defence. Biol. Lett. 2006, 2, 348-350. [CrossRef]

34. Prudic, K.L.; Skemp, A.K.; Papaj, D.R. Aposematic coloration, luminance contrast, and the benefits of conspicuousness. Behav. Ecol. 2007, 18, 41-46. [CrossRef]

35. Hill, G.E. Redness as a measure of the production cost of ornamental coloration. Ethol. Ecol. Evol. 1996, 8, 157-175. [CrossRef]

36. Talloen, W.; Van Dyck, H.; Lens, L. The cost of melanization: Butterfly wing coloration under environmental stress. Evolution 2004, 58, 360-366. [CrossRef]

37. Zamora-Camacho, F.J. Locomotor performance in a running toad: Roles of morphology, sex and agrosystem versus natural habitat. Biol. J. Linn. Soc. 2018, 123, 411-421. [CrossRef]

38. Zechmeister, L. Progress in the Chemistry of Organic Natural Products; Springer: Cham, Switzerland, 1948.

39. Llewelyn, J.; Bell, K.; Schwarzkopf, L.; Alford, R.A.; Shine, R. Ontogenetic shifts in a prey's chemical defences influence feeding responses of a snake predator. Oecologia 2012, 169, 965-973. [CrossRef]

40. Blennerhassett, R.A.; Bell-Anderson, K.; Shine, R.; Brown, G.P. The cost of chemical defence: The impact of toxin depletion on growth and behaviour of cane toads (Rhinella marina). Proc. R. Soc. B 2019, 286, 20190867. [CrossRef] [PubMed]

41. Zamora-Camacho, F.J. Sex and habitat differences in size and coloration of an amphibian's poison glands match differential predator pressures. Integr. Zool. 2021, in press. [CrossRef] [PubMed]

42. Frétey, T.; Cam, E.; Le Garff, B.; Monnat, J.Y. Adult survival and temporary emigration in the common toad. Can. J. Zool. 2004, 82, 859-872. [CrossRef]

43. Gomez-Mestre, I. Sapo corredor-Epidalea calamita (Laurenti, 1768). In Enciclopedia Virtual de los Vertebrados Españoles; Salvador, A., Marco, A., Eds.; Museo Nacional de Ciencias Naturales: Madrid, Spain, 2014. Available online: http:/ / www.vertebradosibericos. org (accessed on 24 November 2021).

44. Stawikowski, R.; Lüddecke, T. Description of defensive postures of the natterjack toad Epidalea calamita (Laurenti 1768) and notes on the release of toxic secretions. Herpetol. Notes 2019, 12, 443-445.

45. Martínez, F.; Montero, G. The Pinus pinea L. woodlands along the coast of South-western Spain: Data for a new geobotanical interpretation. Plant Ecol. 2004, 175, 1-18. [CrossRef]

46. Zamora-Camacho, F.J.; Comas, M. Beyond sexual dimorphism and habitat boundaries: Coloration correlates with morphology, age, and locomotor performance in a toad. Evol. Biol. 2019, 46, 60-70. [CrossRef]

47. Montgomerie, R. Analyzing colors. In Bird Coloration Volume I: Mechanisms and Measurements; Hill, G.E., McGraw, K.J., Eds.; Harvard University Press: Cambridge, MA, USA, 2006.

48. Nguyen, L.P.; Nol, E.; Abraham, K.F. Using digital photographs to evaluate the effectiveness of plover egg crypsis. J. Wildl. Manag. 2007, 71, 2084-2089. [CrossRef]

49. Moreno-Rueda, G.; González-Granda, L.G.; Reguera, S.; Zamora-Camacho, F.J.; Melero, E. Crypsis decreases with elevation in a lizard. Diversity 2019, 11, 236. [CrossRef]

50. Walvoord, M.E. Cricket frogs maintain body hydration and temperature near levels allowing maximum jump performance. Physiol. Biochem. Zool. 2003, 76, 825-835. [CrossRef] [PubMed]

51. Prates, I.; Angilleta, M.J.; Wilson, R.S.; Niehaus, A.C.; Navas, C.A. Dehydration hardly slows hopping toads (Rhinella granulosa) from xeric and mesic environments. Physiol. Biochem. Zool. 2013, 86, 451-457. [CrossRef]

52. Preest, M.R.; Pough, F.H. Interaction of temperature and hydration on locomotion of toads. Funct. Ecol. 1989, 3, 693-699. [CrossRef]

53. Vanhooydonck, B.; Measey, J.; Edwards, S.; Makhubo, B.; Tolley, K.A.; Herrel, A. The effects of substratum on locomotor performance in lacertid lizards. Biol. J. Linn. Soc. 2015, 115, 869-881. [CrossRef]

54. Preest, M.R.; Pough, F.H. Effects of body temperature and hydration state on organismal performance of toads, Bufo americanus. Physiol. Biochem. Zool. 2003, 76, 229-239. [CrossRef]

55. Martín, J.; López, P. Hindlimb asymmetry reduces escape performance in the lizard Psammodromus algirus. Physiol. Biochem. Zool. 2001, 74, 619-624. [CrossRef]

56. Zamora-Camacho, F.J.; Reguera, S.; Rubiño-Hispán, M.V.; Moreno-Rueda, G. Effects of limb length, body mass, gender, gravidity, and elevation on escape speed in the lizard Psammodromus algirus. Evol. Biol. 2014, 41, 509-517. [CrossRef]

57. Quinn, G.P.; Keough, M.J. Experimental Design and Data Analysis for Biologists; Cambridge University Press: Cambridge, MA, USA, 2002.

58. Zamora-Camacho, F.J.; Comas, M.; Moreno-Rueda, G. Immune challenge does not impair short-distance escape speed in a newt. Anim. Behav. 2020, 167, 101-109. [CrossRef]

59. Wirsing, A.J.; Cameron, K.E.; Heithaus, M.R. Spatial responses to predators vary with prey escape mode. Anim. Behav. 2010, 79, 531-537. [CrossRef] 
60. Ben-Hamo, M.; Downs, C.J.; Burns, D.J.; Pinshow, B. House sparrows offset the physiological trade-off between immune response and feather growth by adjusting foraging behavior. J. Avian Biol. 2017, 48, 837-845. [CrossRef]

61. Yu, Z.; Yin, D.; Hou, M.; Zhang, J. Effects of food availability on the trade-off between growth and antioxidant responses in Caenorhabditis elegans exposed to sulfonamide antibiotics. Chemosphere 2018, 211, 278-285. [CrossRef] [PubMed]

62. Sinsch, U. Temporal spacing of breeding activity in the natterjack toad, Bufo calamita. Oecologia 1988, 76, 399-407. [CrossRef]

63. Miaud, C.; Sanuy, D.; Avrillier, J.N. Terrestrial movements of the natterjack toad Bufo calamita (Amphibia, Anura) in a semi-arid, agricultural landscape. Amphib. Reptil. 2009, 21, 357-369.

64. Lodé, T. Sexual dimorphism and trophic constraints: Prey selection in the European polecat (Mustela putorius). Écoscience 2003, 10, 17-23. [CrossRef]

65. Maan, M.E.; Cummings, M.E. Sexual dimorphism and directional sexual selection on aposematic signals in a poison frog. Proc. Nat. Acad. Sci. USA 2009, 106, 19072-19077. [CrossRef]

66. Carlson, B.E.; McGinley, S.; Rowe, M.P. Meek males and fighting females: Sexually-dimorphic antipredator behavior and locomotor performance is explained by morphology in bark scorpions (Centruroides vittatus). PLoS ONE 2014, 9, e97648. [CrossRef]

67. Gaynor, K.M.; Brown, J.S.; Middleton, A.D.; Power, M.E.; Brashares, J.S. Landscapes of fear: Spatial patterns of risk perception and response. Trends Ecol. Evol. 2019, 34, 355-368. [CrossRef]

68. McIntosh, A.R.; Townsend, C.R. Interpopulation variation in mayfly antipredator tactics: Differential effects of contrasting predatory fish. Ecology 1994, 75, 2078-2090. [CrossRef]

69. Sirot, E. Adjustments in compound defensive strategies in response to variation in predation risk. Anim. Behav. 2019, 147, 53-60. [CrossRef] 